\title{
Dodecahedral W@WC Composite as Efficient Catalyst for Hydrogen Evolution and Nitrobenzene Reduction Reactions
}

\author{
Zhao-Yang Chen, ${ }^{\dagger}$ Long-Fa Duan, ${ }^{\dagger}$ Tian Sheng, ${ }^{\S}$ Xiao Lin, ${ }^{\|}$Ya-Feng Chen, ${ }^{\ddagger}$ You-Qun Chu, ${ }^{*}{ }^{\dagger}$ \\ Shi-Gang Sun, ${ }^{\S}$ and Wen-Feng Lin ${ }^{*}+\bullet$
}

\begin{abstract}
${ }^{\dagger}$ State Key Laboratory Breeding Base for Green Chemistry Synthesis Technology, International Sci. \& Tech. Cooperation Base of Energy Materials and Application, College of Chemical Engineering and Materials Science, Zhejiang University of Technology, 18 Chaowang Road, Hangzhou 310032, P. R. China

${ }^{\ddagger}$ Department of Chemical Engineering, Loughborough University, Loughborough, Leicestershire, LE11 3TU, United Kingdom

${ }^{\S}$ Collaborative Innovation Center of Chemistry for Energy Materials, State Key Laboratory of Physical Chemistry of Solid Surfaces, College of Chemistry and Chemical Engineering, Xiamen University, Xiamen, 361005, P. R. China

"Department of Chemical Engineering and Biotechnology, University of Cambridge, Cambridge CB2 3RA, United Kingdom
\end{abstract}

Supporting Information

ABSTRACT: Core-shell composites with strong phase-phase contact could provide an incentive for catalytic activity. A simple, yet efficient, $\mathrm{H}_{2} \mathrm{O}$-mediated method has been developed to synthesize a mesoscopic core-shell W@WC architecture with a dodecahedral microstructure, via a one-pot reaction. The $\mathrm{H}_{2} \mathrm{O}$ plays an important role in the resistance of carbon diffusion, resulting in the formation of the $\mathrm{W}$ core and $\mathrm{W}$ terminated WC shell. Density functional theory (DFT) calculations reveal that adding W as core reduced the oxygen adsorption energy and provided the $\mathrm{W}$-terminated WC surface. The W@WC exhibits significant electrocatalytic activities toward hydrogen evolution and nitrobenzene electroreduction reactions, which are comparable to those found for commercial $\mathrm{Pt} / \mathrm{C}$, and substantially higher than those found for meso- and nano-WC materials. The experimental results were explained by DFT calculations based on the energy profiles in the hydrogen evolution reactions over WC, W@WC, and Pt model surfaces. The W@WC also shows a high thermal stability and thus may serve as a

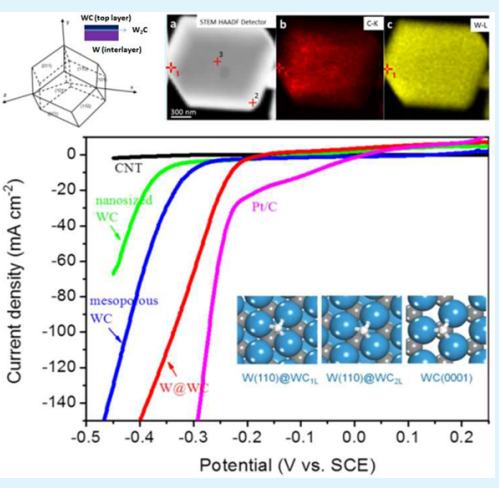
promising more economical alternative to Pt catalysts in these important energy conversion and environmental protection applications. The current approach can also be extended or adapted to various metals and carbides, allowing for the design and fabrication of a wide range of catalytic and other multifunctional composites.

KEYWORDS: tungsten, tungsten carbide, core-shell structure, self-assembly, electrocatalyst, density functional theory, hydrogen evolution

\section{INTRODUCTION}

Composite materials are fundamentally important in both academic studies and industrial applications. Incorporation of bi- or tri-component materials can improve insufficient activity possessed by single component materials. Studies have shown that the surface structure of a composite has a strong influence on its stability and catalytic properties. ${ }^{1-3}$ Transition metal carbides such as $\mathrm{WC}, \mathrm{TiC}$, and $\mathrm{MoC}$ and their composites are becoming increasing important due to their diverse physical and chemical properties for various applications. ${ }^{4-9}$ WC materials, in particular, have demonstrated platinum-like surface properties in many surface science and catalysis studies, including those initially investigated by Levy and Boudart ${ }^{10}$ and more recently by Bosco. ${ }^{11}$

To date, many investigations have paid attention on increasing the specific surface area of WC to improve the (electro)-catalytic activity. However, WC (or WC/C composites) materials with high surface area still show a low activity. ${ }^{11}$ Our previous research has focused on the catalytic improve- ment of WC single-phase materials and WC composites. ${ }^{3,12-14}$ Nanosized and mesoporous WC materials were prepared which did exhibt improved electrocatalytic actvity; nevertheless, they are still incomparable with the commercial Pt catalysts. The main difficulty for improving activity seems to be due to the fact that carburization requires a high temperature which reduces the possibility of controlling the surface structure. Chen and his group have shown that tungsten carbides are a class of materials very challenging to work on due to complications related to carbon, oxides and defects being present on surface, as well as phase purity and surface termination. ${ }^{15-17}$ Surface reactivity toward chemisorption and catalysis are often inhibited by polymeric carbon deposited on carbide surfaces during the carburization processes. ${ }^{18}$ It was believed that the most active WC was slightly carbon deficient in the carbon layers of the

Received: March 28, 2017

Accepted: May 31, 2017

Published: May 31, 2017 
WC lattice. ${ }^{19}$ However, the challenges of synthesizing and maintaining a clean (free from deposited carbon and with $\mathrm{W}$ terminated) and stable WC surface still need to be overcome.

Typically, the $\mathrm{W}$ precursor (ammonium tungstate) was carburized to form WC at $850{ }^{\circ} \mathrm{C}$. Although the WC surface exhibits as normal WC planes, some $\mathrm{C}$ vacancies would be inevitably replaced by $\mathrm{O}$ atoms. ${ }^{20,21}$ These in turn would resist the exposure of the $\mathrm{W}$-terminated surface. During the catalytic reaction, the $\mathrm{O}$ atoms should be removed to reactivate the $\mathrm{W}$ terminated WC surface layer. Following the progress of our understanding, we are interested in developing the WC composite with strong phase-phase bonding to further improve the catalytic activity through exposing the $\mathrm{W}$ terminated WC surface layer. Engineering a composite having a multilayer structure with WC as the surface layer and carbonfree materials as the bottom layer is considered as an effective way to balance these surface properties for resisting the trend of carbon atoms being transported outward. We expect that the core-shell W@WC structure with mixed W-terminated WC shell is a promising candidate, as using $\mathrm{W}$ as the core can combine favorable properties of a core-shell structure,,$^{22,23}$ as well as reduce the surface $\mathrm{O}$ adsorption energy.

In this work, we propose and demonstrate a simple, yet novel, method to synthesize W@WC bilayer particles with a primary W-terminated WC top layer. $\mathrm{H}_{2} \mathrm{O}$, serving as a clean "catalyst", mediated the direction of crystal growth. This is a one-pot and scalable synthsis method and is capable to be adapted to produce multifuctional WC based materials in largescale.

\section{EXPERIMENTAL AND MODELING SECTION}

2.1. Synthesis of W@WC. Ammonium metatungstate (AMT, $(\mathrm{NH} 4)_{2} \mathrm{~W}_{4} \mathrm{O}_{13} \cdot x \mathrm{H}_{2} \mathrm{O}$ ) was dissolved in deionized water with a weight percentage of $10 \%$ and then treated by spray-drying (BÜCHI Spray Dryer B-290) to produce hollow spheres. The precursor was prepared in a corundum boat and dried in a tube furnace under flowing nitrogen gas for $1 \mathrm{~h}$. This sample underwent the gas-solid reaction under an atmosphere of $\mathrm{CO} / \mathrm{CO}_{2} / \mathrm{H}_{2} \mathrm{O}$. The schematic diagram of the setup used for the synthesis of W@WC is shown in the SI (Figure S2). The flow rates of $\mathrm{CO}$ and $\mathrm{CO}_{2}$ gases were 300 and $30 \mathrm{~cm}^{3} \mathrm{~min}^{-1}$, respectively. Initially, furnace temperature was raised to $400{ }^{\circ} \mathrm{C}$ and maintained for $2 \mathrm{~h}$ after the reaction zone was free from oxygen. The water was introduced by vaporizing deionized water to wet the airflow at the entrance of the reaction zone. Thereafter, the temperature was raised to $850^{\circ} \mathrm{C}$ and maintained for $12 \mathrm{~h}$. The sample was cooled to 0 ${ }^{\circ} \mathrm{C}$ at the end of the reaction.

2.2. Characterization. The phases present in the synthesized material were identified using XRD (Panalytical X'Pert Pro) and TGA (Seiko Instruments, Pyris Diamond). The morphology and structure of the products were characterized using FE-SEM (Hitachi S-4700 II) and TEM (Tecnai G2 F30) and HR-TEM with EDS. The specific surface areas of the sample pores were measured by a nitrogen adsorption-desorption analyzer (Micromeritics ASAP 2020). The surface compositions of the resultant microparticles were detected by the XPS recorded on a Kratos AXIS Ultra DLD, using a monochromated $\mathrm{Al} \mathrm{K} \alpha \mathrm{X}$-ray as the excitation source, and the binding energies were corrected using $\mathrm{Au} 4 \mathrm{f}_{7 / 2}(84.0 \mathrm{eV})$ as the reference line.

2.3. Electrochemical Measurements. The electrocatalytic properties of the W@WC were analyzed by employing the powder microelectrode (PME, $60 \mu \mathrm{m}$ in diameter) approach. The structure and preparation of the PME have been described previously. ${ }^{24}$ The WC samples were ground and inserted into the lower tip of the electrode. ${ }^{25}$ Cyclic voltammetry of W@WC was carried out using an electrochemical station (CHI-660c), where reduction current is defined as positive current.
2.4. DFT Calculation Method. All the electronic structure calculations were performed using the Vienna Ab-initio Simulation Package (VASP) with the exchange-correlation functional of PerdewBurke-Ernzerhof (PBE). The projector-augmented wave (PAW) pseudopotentials were utilized to describe the core electron interaction. Geometry optimization was carried out by the BFGS algorithm. ${ }^{26-33}$ The cutoff energy was $400 \mathrm{eV}$, and a $4 \times 4 \times 1$ Monkhorst-Pack $k$-point sampling was used. Four layers of the Wterminated $\mathrm{WC}(0001)$ surface was used in the calculation. For modeling the W@WC materials, the $p(3 \times 3) \mathrm{W}(110)$ surface was used as the core structure and $\mathrm{C}$ atoms were set up in the first and second subsurface, keeping the ratio of $\mathrm{W}: \mathrm{C}$ equal to $1: 1$. We modeled $\mathrm{W}(110) @ \mathrm{WC}_{1 \mathrm{~L}}$ [one layer of WC on W(110)] and W(110)@WC [two layers of WC on W(110)] surfaces with different quantities of $\mathrm{C}$ atoms to represent the W(@WC materials. The bottom two layers were fixed while the top two layers were allowed to relax during calculations. The vacuum region was $\sim 12 \AA$ to ensure that there is little interaction between slabs. The top and side views of the models are shown in Figure S1. For each adsorbate, different binding sites were calculated to determine the most stable bonding configuration. The adsorption energy was defined as eq 1

$$
E_{\mathrm{ad}}=E(\text { adsorbate } / \text { surface })-E(\text { adsorbate })-E(\text { surface })
$$

where $E$ (adsorbate/surface), $E$ (adsorbate), and $E$ (surface) are the total energies of the adsorbate binding with the surface, gaseous adsorbate, and clean surface, respectively. The Gibbs free energy can be written as $G=E+\mathrm{ZPE}-T S$, where ZPE is the zero point energy, $S$ is the entropy, and $T$ is the temperature of $298.15 \mathrm{~K}$.

2.5. DFT Calculations of Catalytic Activity toward Hydrogen Evolution Reaction (HER). Norskov's group have provided a theoretical model to explain the origin of the volcano curve in HER kinetically, which is in good agreement with experiments and has been widely used in the understanding of the catalytic activity in hydrogen evolution reactions. ${ }^{34-37}$ In this general model, the kinetics is determined by the hydrogen adsorption free energy, $\Delta G\left(\mathrm{H}^{*}\right)$.

The total hydrogen evolution reaction can be written as

$$
2 \mathrm{H}^{+}+2 \mathrm{e}^{-} \rightarrow \mathrm{H}_{2}
$$

The reaction 2 is in equilibrium at the condition of standard hydrogen electrode (SHE) $(\mathrm{pH}=0, T=298.15 \mathrm{~K})$, and therefore, the free energy of $\mathrm{H}^{+}+\mathrm{e}-$ is equal to that of $1 /{ }_{2} \mathrm{H}_{2}$. The reaction 2 can be decomposed into two steps as reactions 3 and 4 . It is noticed that, in this model, the role of the Tafel reaction $\left(2 \mathrm{H}^{*} \rightarrow \mathrm{H}_{2}\right)$ is proved to be limited.

$$
\begin{aligned}
& \mathrm{H}^{+}+\mathrm{e}^{-} \rightarrow \mathrm{H}^{*} \\
& \mathrm{H}^{*}+\mathrm{H}^{+}+\mathrm{e}^{-} \rightarrow \mathrm{H}_{2}
\end{aligned}
$$

Since the reaction barriers are limited by the thermodynamical states, the total reaction rate can be deduced as eq 5

$$
r=k_{\mathrm{B}} T / h \exp \left\{-\max \left(\Delta G_{2}, \Delta G_{3}\right) / R T\right\}
$$

where $\Delta G_{2}$ and $\Delta G_{3}$ are the free energy changes of the following reactions 6 and 7 , respectively.

$$
\begin{aligned}
& \Delta G_{2}=G\left(\mathrm{H}^{*}\right)-G\left(\mathrm{H}^{+}+\mathrm{e}^{-}\right) \\
& \Delta G_{3}=G\left(\mathrm{H}_{2}\right)-G\left(\mathrm{H}^{*}\right)-G\left(\mathrm{H}^{+}+\mathrm{e}^{-}\right)
\end{aligned}
$$

\section{RESULTS AND DISCUSSION}

3.1. Theoretical Structural Analysis. The density functional theory (DFT) calculations were performed on oxygen adsorption on W(110)@WC $\mathrm{WC}_{1 \mathrm{~L}}$ (one layer of WC shell), $\mathrm{W}(110) @ \mathrm{WC}_{2 \mathrm{~L}}$ (two layers of WC shell), and WC(0001) surfaces at various oxygen coverages of $0.33,0.67$, and $1 \mathrm{ML}$, respectively. The relationship between the oxygen adsorption free energy, $\Delta G\left(\mathrm{O}^{*}\right)$, and the coverage, $\theta\left(\mathrm{O}^{*}\right)$, is shown in Figure 1 . Atomic oxygen prefers to occupy the surface hollow 
a

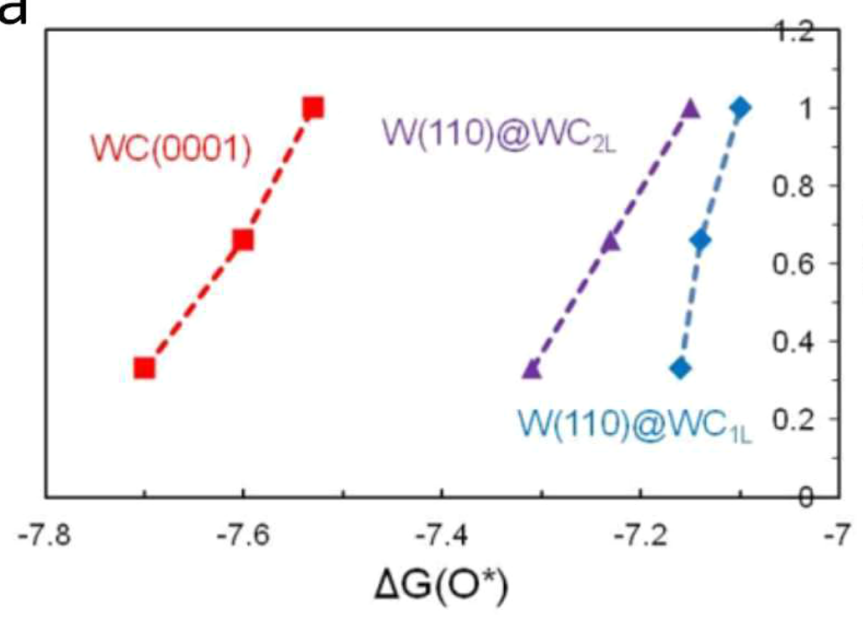

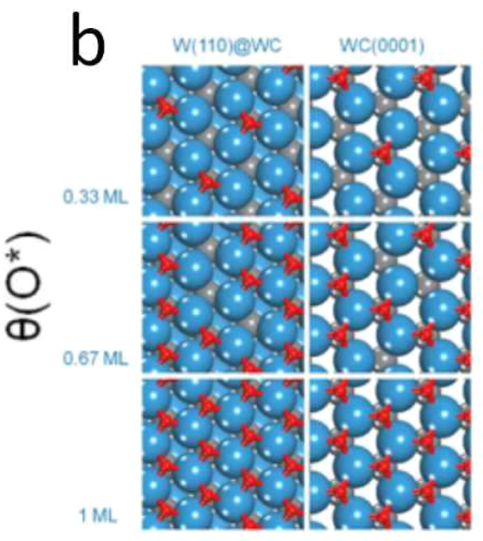

Figure 1. (a) Calculated oxygen adsorption free energy, $\Delta G\left(\mathrm{O}^{*}\right)$, at various oxygen coverages, $\theta\left(\mathrm{O}^{*}\right)=0.33,0.67$, and $1 \mathrm{ML}$, on $\mathrm{W}(110) @ \mathrm{WC}$ L (that is one layer of WC shell on top of W core), W(110)@WC $\mathrm{W}_{2 \mathrm{~L}}$ (that is 2 layers of WC shell on top of W core), and WC(0001) surfaces. (b) Models showing different oxygen coverages on WC(110)@WC and WC(0001) surfaces.


Figure 2. $(a-d)$ SEM images showing the morphologies of (a) the spherical precursor of ammonium metatungstate and (b-d) the dodecahedral W@WC product. (e) TEM image of a nanosized W@WC particle. (f) HRTEM image showing the edge of the dodecahedral particle. (g) Model showing the relationship between the dodecahedral shape and the crystal planes.

site (Figure 1). Oxygen on WC(0001) yields the highest adsorption free energy in the range of -7.53 to $-7.70 \mathrm{eV}$. However, on W(110)@WC $\mathrm{WL}_{1 \mathrm{~L}}$, the oxygen adsorption free energy is decreased significantly to -7.09 to $-7.16 \mathrm{eV}$, much lower than those on $\mathrm{WC}(0001)$, indicating weaker $\mathrm{O}$ adsorption over the composite surface.

Compared to WC, atomic oxygen on W@WC is significantly easier to be reduced/removed with ca. $0.40 \mathrm{~V}$ less overpotential 
(0.4 eV less in oxygen adsorption energy; see Figures 1 and $\mathrm{S} 1)$, resulting in more $\mathrm{W}$-terminated sites available for catalytic reactions.

3.2. $\mathrm{H}_{2} \mathrm{O}$-Mediated Synthesis of W@WC. 3.2.1. Material Characterization. The W@WC was synthesized via a one-pot method in a tube furnace (see Figure S2) by carburizing the spray dried precursor (ammonium metatungstate, AMT; see Figure 2a for its morphology). Scanning electron microscopy (SEM) of the W@WC sample revealed the dodecahedral morphology (Figure $2 b-d$ ).

The surface of the W@WC is smooth and free of pores. The layered structure of the as-synthesized sample was also observed by powder X-ray diffraction (XRD) analysis (curve $850{ }^{\circ} \mathrm{C}-12 \mathrm{~h}$, Figure 3 ). The most intense diffraction peaks

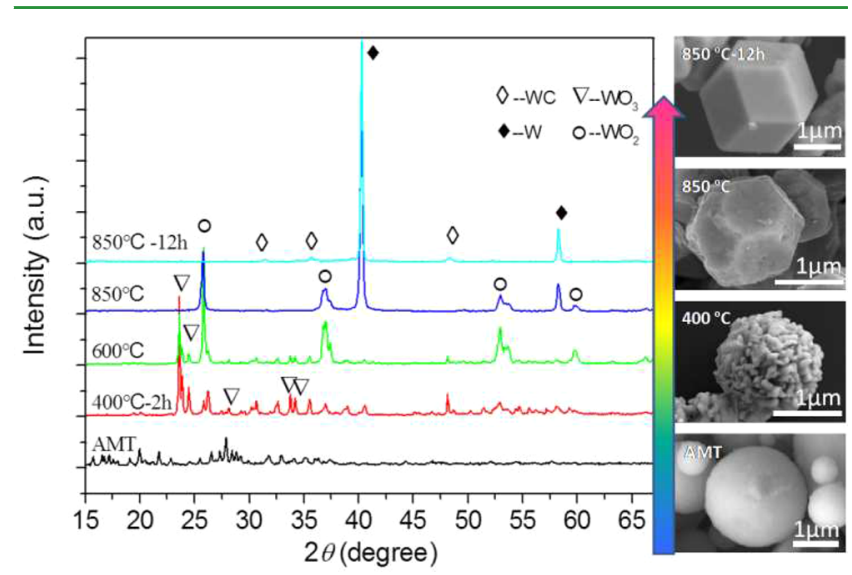

Figure 3. XRD patterns and SEM images of the sample at each stage of the reduction-carburization process.

were found at $2 \theta$ values of $40.3^{\circ}$ and $58.3^{\circ}$, which are consistent with the planes of $\mathrm{W}(110)$ and $\mathrm{W}(200)$ in JCPDS 04-0806. In addition, there are several additional diffraction peaks with $2 \theta$ values of $31.5,35.7$, and $48.4^{\circ}$ (Figure 3 and the inset in Figure $4 \mathrm{a})$, which can be assigned to the planes of $\mathrm{WC}(001), \mathrm{WC}(100)$, and $\mathrm{WC}(101)$, respectively, according to JCPDS 25-1047.

To get an insight into the route of the W@WC formation, XRD patterns and SEM images of the sample at each stage of the reduction-carburization process were collected (Figure 3).
Below $400{ }^{\circ} \mathrm{C}$, the spherical AMT underwent decomposition and dehydration, forming $\mathrm{WO}_{3}$ predominantly. Between 400 and $850{ }^{\circ} \mathrm{C}$, the sample was reduced in the presence of $\mathrm{CO}$, forming $\mathrm{W}$ predominantly.

3.2.2. Synthesis Mechanism. It is noted that CO not only acted as a reductive agent for reducing tungsten oxide but also underwent the following redox reaction (i.e., Boudouard reaction):

$$
2 \mathrm{CO}(\mathrm{g}) \rightarrow \mathrm{CO}_{2}(\mathrm{~g})+\mathrm{C}(\mathrm{s})
$$

The dynamic ratio of $\mathrm{CO} / \mathrm{CO}_{2}$ in the tube furnace was determined by the Boudouard reaction (eq 8); at temperatures below $700{ }^{\circ} \mathrm{C}$, the predominant products were on the $\mathrm{CO}_{2}$ (exothermic formation) side, whereas, at higher temperatures, the most dominant product was $\mathrm{CO}$ (endothermic formation process). Here, $\mathrm{CO}_{2}$ was added in the reaction atmosphere to inhibit "Boudouard reaction", and the following water-gas shift reaction became the dominant process at the lower temperatures, which being weakly exothermic (eq 9). ${ }^{38}$

$$
\mathrm{CO}(\mathrm{g})+\mathrm{H}_{2} \mathrm{O}(\mathrm{g}) \rightarrow \mathrm{CO}_{2}(\mathrm{~g})+\mathrm{H}_{2}(\mathrm{~g})
$$

The presence of $\mathrm{H}_{2} \mathrm{O}$ vapor resulted in the production of hydrogen as a secondary reductive agent. During this stage, the macroporous structure of $\mathrm{WO}_{3}$ was already formed (below 400 ${ }^{\circ} \mathrm{C}$ ) on removal of the $\mathrm{NH}_{3}$ upon decomposition of the $\mathrm{NH}_{4}^{+}$ contained in the AMT. $\mathrm{H}_{2} \mathrm{O}$ was also released from the AMT, and it was unlikely to be removed away from the sample as there was abundant $\mathrm{H}_{2} \mathrm{O}$ added in the carburization atmosphere. $\mathrm{H}_{2} \mathrm{O}$ reacted with $\mathrm{WO}_{3}$ to form gaseous $\mathrm{WO}_{2}(\mathrm{OH})_{2}$ (eq 10; also see Figure S3). ${ }^{39}$

$$
\mathrm{WO}_{3}(\mathrm{~s})+\mathrm{H}_{2} \mathrm{O}(\mathrm{g}) \rightarrow \mathrm{WO}_{2}(\mathrm{OH})_{2}(\mathrm{~g})
$$

$\mathrm{WO}_{2}(\mathrm{OH})_{2}$ was then reduced by $\mathrm{H}_{2}$ to form $\mathrm{W}$ in accordance with the eq 11 , where $\mathrm{W}$ crystallization proceeded as it was being produced.

$$
\mathrm{WO}_{2}(\mathrm{OH})_{2}(\mathrm{~g})+3 \mathrm{H}_{2}(\mathrm{~g}) \rightarrow \mathrm{W}(\mathrm{s})+4 \mathrm{H}_{2} \mathrm{O}(\mathrm{g})
$$

According to the Wulff facets theorem, ${ }^{40}$ a crystal formed at equilibrium has to be bound by facets giving a minimum total surface energy. For a body-centered cubic (bcc) crystal structure such as W, the surface energy of the low-index crystallographic facets is given in the order $\gamma\{110\}<\gamma\{100\}<$ $\gamma\{111\}$. $^{4}$ Here, $\mathrm{H}_{2} \mathrm{O}$ was added as the catalyst to produce
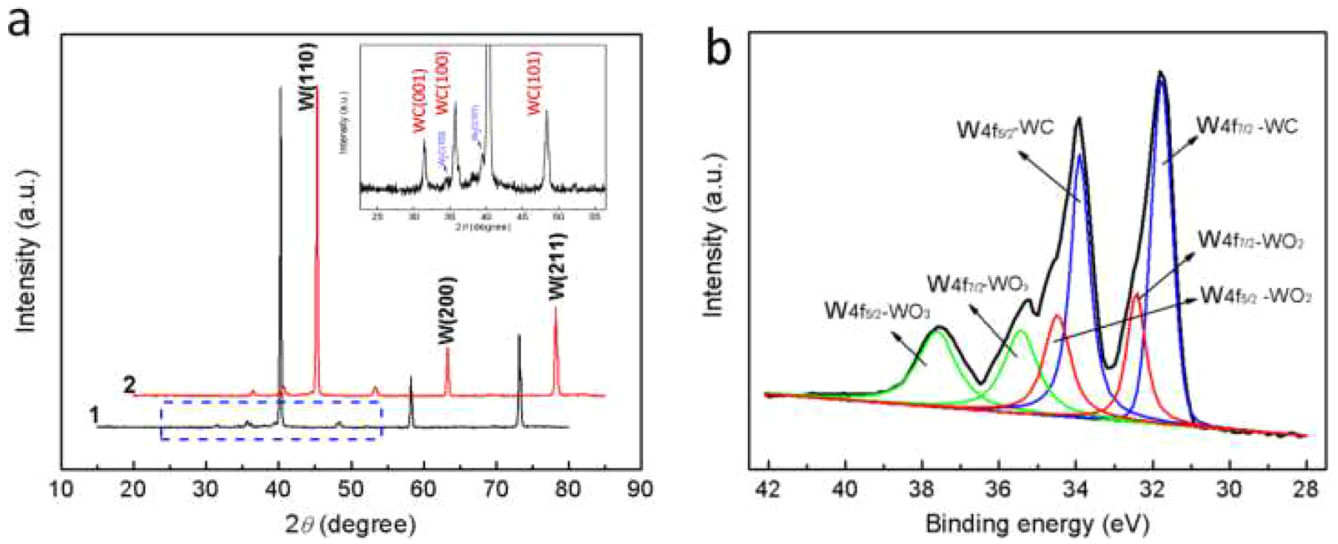

Figure 4. (a) The XRD patterns of the carburized W@WC sample (1) and the same sample following a second carburization process at $850{ }^{\circ} \mathrm{C}(2)$; the inset shows a magnified XRD pattern of the carburized sample. (b) XPS of W 4f features for the W@WC bilayers (black line corresponds to the overall spectrum, and the colored lines indicate curve fitting of the $4 \mathrm{f}_{7 / 2}$ and $4 \mathrm{f}_{5 / 2}$ spin orbit coupling pairs). 
gaseous $\mathrm{WO}_{2}(\mathrm{OH})_{2}$ as the intermediate (eqs 10 and 11). The absence of crystallization medium in the gas-solid reaction can thus be avoided. On the basis of these factors, the minimum surface-energy requirement predicts that the seed crystals of $\mathrm{W}$ should show a tendency to adopt a dodecahedron shape enclosed by $\{110\}$ facets. ${ }^{42}$ With a high extent of epitaxial growth at high temperature, the aggregates of nanocrystallites form a continuous crystal (Figure 3, SEM images). ${ }^{43}$ On the other hand, for a comparison, we also used pure and dry $\mathrm{H}_{2}$ gas directly to reduce the spherical AMT; the yielded particles exhibit a mesoporous structure (Figure S4) rather than the dodecahedral W@WC having the smooth surface.

Due to the loss of volatilizing components $\left(\mathrm{H}_{2} \mathrm{O}, \mathrm{NH}_{3}\right)$ in the AMT precursor and the instant reduction of $\mathrm{WO}_{2}(\mathrm{OH})_{2}$, the particle size distribution of the dodecahedral W@WC product was largely following the spherical AMT precursor with a little narrowing tendency (Figure S5).

Carburization of the $\mathrm{W}$ surface could also take place via the exothermic methane formation as well as via the direct $\mathrm{CO}$ reaction to form $\mathrm{WC}$ in the following reactions:

$$
\begin{aligned}
& \mathrm{CO}(\mathrm{g})+3 \mathrm{H}_{2}(\mathrm{~g}) \rightarrow \mathrm{CH}_{4}(\mathrm{~g})+\mathrm{H}_{2} \mathrm{O}(\mathrm{g}) \\
& \mathrm{W}(\mathrm{s})+2 \mathrm{CO}(\mathrm{g}) \rightarrow \mathrm{WC}(\mathrm{s})+\mathrm{CO}_{2}(\mathrm{~g}) \\
& \mathrm{W}(\mathrm{s})+\mathrm{CH}_{4}(\mathrm{~g}) \rightarrow \mathrm{WC}(\mathrm{s})+2 \mathrm{H}_{2}(\mathrm{~g})
\end{aligned}
$$

Carburization depends on the atomic arrangement, the mass of the atom, and the temperature. ${ }^{44}$ During the carburizing procedure, carbon may diffuse through and carburize the $\mathrm{W}$ lattices (Figure 2g). The exposed $\{110\}$ facets are considered as ideal for carburization resistance as they possess high W surface densities and narrow empty channels for carbon diffusion. The resistance facilitates narrowing the WC layer, which would favor to reducing the oxygen adsorption free energy (Figure 1). The integrated mechanism for the formation of the W@WC with a dodecahedral microstructure proposed is shown schematically (Figure S6).

It is clear that $\mathrm{H}_{2} \mathrm{O}$ plays a key role as a structure-directing agent by mediating the crystal growth of $\mathrm{W}$ along the $\{110\}$ facets to form a stable dodecahedron shape. At the carburization stage, only a thin layer of WC was formed on the surface due to the aforementioned resistance of the $\{110\}$ facets to carburization.

Transmission electron microscopy (TEM) of the product confirmed a core-shell structure of the W@WC (Figure 2e). The high-resolution TEM image (Figure 2f) taken on the edge of a particle (see the inset in Figure $2 \mathrm{f}$ ) shows the exposed $\{001\},\{100\}$, and $\{101\}$ facets of WC, thus confirming that the surface layer formed is the carbide. These results further confirm that the sample is composed of W and WC with a trace amount of $\mathrm{W}_{2} \mathrm{C}$ as the intermediate layer (Figure 4a). The XRD data match the W@WC structural features observed in the TEM analysis. Scanning-TEM (STEM) and STEM-energy dispersive X-ray spectroscopy (STEM-EDS) (Figure S7) further confirm the formation of a uniform top layer of WC on the $\mathrm{W}$ core, with ca. 1:9 for the shell:core thickness ratio, in good agreement with the XRD and HRTEM results.

The physical-chemical stability of the W@WC determines the corrosion/oxidation resistance. As shown in the XRD pattern obtained following a second carburization process at $850{ }^{\circ} \mathrm{C}$ with dry $\mathrm{CO} / \mathrm{CO}_{2}\left(\mathrm{H}_{2} \mathrm{O}\right.$-free $)$, the $\mathrm{W}$ diffractogram in the sample still remains (diffractogram 2 in Figure 4a), confirming good thermal stability of the W@WC. The resistance to carbon diffusion was clearly evidenced here from the presence of the dodecahedral $\mathrm{W}$ core which can only be formed in the presence of $\mathrm{H}_{2} \mathrm{O}$. A reference sample was synthesized by carburizing the same precursor with dry $\mathrm{CO} /$ $\mathrm{CO}_{2}$. The XRD, SEM, and pore size distribution data (Figure S8) indicate that the product consists of pure WC with a mesoporous structure. Significant thermal stability of the W@ WC in the air was evidenced by its high oxidation temperature. The weight gain associated with the oxidation of W@WC begins at ca. $602{ }^{\circ} \mathrm{C}$, which is compared with ca. $475{ }^{\circ} \mathrm{C}$ found in the case of a pure WC sample (Figure S9a,b) and also 601 ${ }^{\circ} \mathrm{C}$ found in the case of a $\mathrm{C}$ protected WC sample. ${ }^{45}$

Thermogravimetric analysis in the air was also used to determine the mass ratio of WC and W in the W@WC sample. Assuming all carbon being removed as $\mathrm{CO}_{2}$, the WC mass was calculated as follows

$$
\begin{aligned}
& m_{\mathrm{wc}}+m_{\mathrm{w}}=m_{\mathrm{i}} \\
& m_{\mathrm{wc}} \times \frac{M_{\mathrm{WO}_{3}}}{M_{\mathrm{WC}}}+m_{\mathrm{w}} \times \frac{M_{\mathrm{WO}_{3}}}{M_{\mathrm{W}}}=m_{\mathrm{wo}_{3}}
\end{aligned}
$$

where $m_{\mathrm{i}}$ is the initial mass; $m_{\mathrm{wc}}$ is the mass of the WC shell; $m_{\mathrm{w}}$ is the mass of the tungsten core and $m_{\mathrm{wo}_{3}}$ is the mass of the oxidation product $\mathrm{WO}_{3}$.

The TG data (Figure S9) showed a large mass gain of ca. 20.2 wt $\%\left[\left(m_{\mathrm{wo}_{3}}-m_{\mathrm{i}}\right) / m_{\mathrm{i}}\right]$ from which the WC content of the sample was estimated to be $20.5 \%$.

As the aforementioned, if the trend of carbon atoms being transported outward was reduced by fabricating the $\mathrm{W}$ core with $\{110\}$ facets, the carbon deficiency ( $\mathrm{W}$-terminated) is readily replaced by oxygen to keep the surface layer stable. After a period of time in the air, the surface compositional information on the prepared W@WC was analyzed by X-ray photoelectron spectroscopy (XPS). W, C, and O, due to the precursor and the carburization atmosphere, were all detected (Figure S10). The curve fitting of the W $4 \mathrm{f}$ spectral lines shows two principal peaks at 31.9 and $33.9 \mathrm{eV}$ (Figure 4b) which are consistent with $\mathrm{W} 4 \mathrm{f}_{7 / 2}$ and $4 \mathrm{f}_{5 / 2}$ peaks, respectively, in WC. ${ }^{46}$ Two other pairs of peaks at 35.9/32.5 eV and 38.0/34.5 eV were also observed which are in agreement with the $4 \mathrm{f}_{7 / 2} / 4 \mathrm{f}_{5 / 2}$ binding energies of the +6 and +4 oxidation states of tungsten in $\mathrm{WO}_{3}$ and $\mathrm{WO}_{2}$, respectively, indicating the presence of $\mathrm{WO}_{x}$ sites on the surface of the WC shell. These results show evidence that, when an oxygen-containing species is present, the formation of tungsten oxycarbide species is possible. ${ }^{47,48}$ In this way, the surface vacancies can be maximally stabilized, where the $\mathrm{O}$ atoms diffuse into the second layer (becoming subsurface $O$ ) to replace the carbons that were bonded to the tungsten.

3.3. Catalytic Properties of W@WC Composite. The catalytic activity of the W@WC was tested for hydrogen evolution reaction (HER), which is a very important reaction in clean energy technologies and also an excellent probe reaction for studying multifunctional catalysts. The main results are shown in Figure 5 where the electrocatalytic performance toward HER can be assessed from the representative polarization curve obtained from the W@WC catalyst, in comparison with a commercial Pt/C catalyst (JM 20 wt \% Pt on carbon) as well as nanosized and mesoporous WC samples, in $0.1 \mathrm{HClO}_{4}$ electrolyte solution; the typical cyclic voltammograms ${ }^{49}$ of the W@WC catalyst and $\mathrm{Pt} / \mathrm{C}$ are shown in Figure S11, confirming the clean surfaces were obtained before 


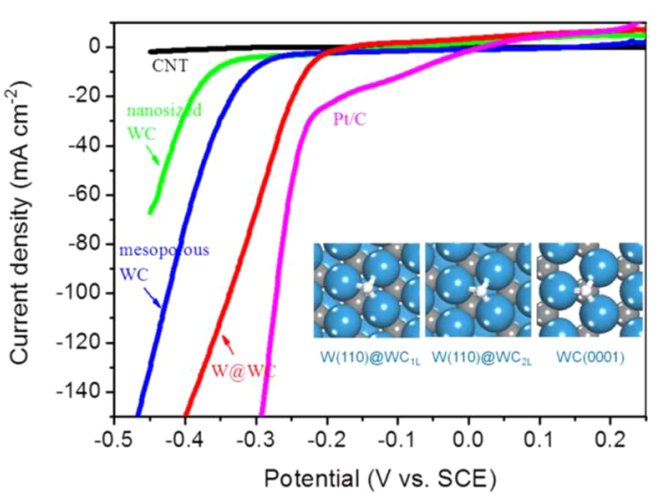

Figure 5. Electrochemical polarization curves showing hydrogen evolution reaction over the W@WC, nanosized WC, mesoporous WC, $\mathrm{Pt} / \mathrm{C}$, and pristine CNT (carbon nanotube) in $0.1 \mathrm{HClO}_{4}$ solution (scan rate: $2 \mathrm{mV} \mathrm{s}^{-1}$ ).

performing the corresponding polarization tests of HER as shown in Figure 5. As expected, the $\mathrm{Pt} / \mathrm{C}$ catalyst exhibited a high catalytic performance for the HER with a reasonable low overpotential $\left(\eta_{\mathrm{i}}\right)$ of $245 \mathrm{mV}\left(\eta_{\mathrm{i}}\right.$ was defined as the potential applied at $50 \mathrm{~mA} \mathrm{~cm}{ }^{-2}$ of cathodic current density of HER), while the nanosized WC requires a much higher overpotential of $428 \mathrm{mV}$ (green line; see Figure 5). Compared to nanosized WC, mesoporous WC exhibited a slightly lower $\eta_{\mathrm{i}}$ of $377 \mathrm{mV}$, which demonstrates that the presence of the mesoporous stucture favors proton reduction kinetics. Very interestingly, W@WC exhibited a much smaller $\eta_{\mathrm{i}}(283 \mathrm{mV}$; see red line, Figure 5) than both nanosized and mesorporous WC, indicating that the unique core-shell structure of W@WC reduces the extra (over)potential (and the corresponding energy) required for the HER. For driving a current density of $100 \mathrm{~mA} \mathrm{~cm}{ }^{-2}$, W@WC only required an overpotential of 337 $\mathrm{mV}$, a performance which is comparable to $\mathrm{Pt} / \mathrm{C}$ (with $\eta_{\mathrm{i}}$ value of $272 \mathrm{mV}$ ).

To get a fundamental understanding of the catalytic activity of W@WC toward HER, DFT atomistic modeling was performed. The free energy profiles in the hydrogen evolution reactions over WC, W@WC, and Pt surfaces were calculated and compared as shown in Figure 6. On the basis of these, the theoretical volcano curve between the hydrogen evolution reaction rate, $\ln \left(r_{\mathrm{HER}}\right)$, and atomic hydrogen adsorption free energy, $\Delta G\left(\mathrm{H}^{*}\right)$, was plotted in Figure 7. It can be seen from Figure 7 that the position of the $\operatorname{Pt}(111)$ surface is near to the

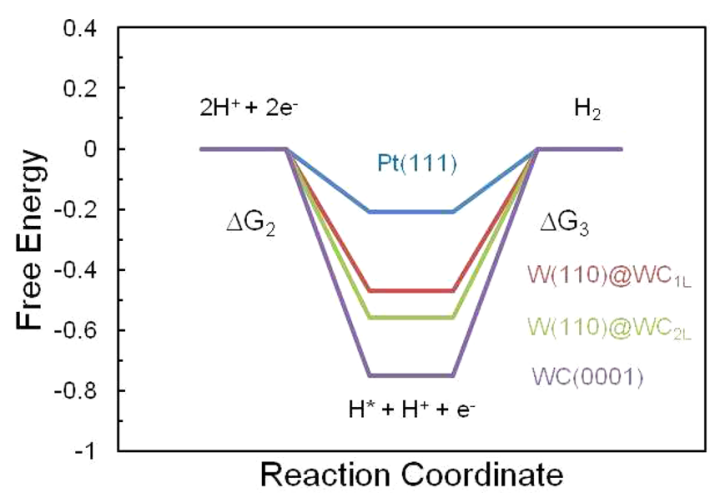

Figure 6. Free energy $(\mathrm{eV})$ profiles of the hydrogen evolution reactions on $\mathrm{Pt}(111), \mathrm{W}(110) @ \mathrm{WC}_{1 \mathrm{~L}}, \mathrm{~W}(110) @ \mathrm{WC}_{2 \mathrm{~L}}$, and $\mathrm{WC}(0001)$ surfaces.

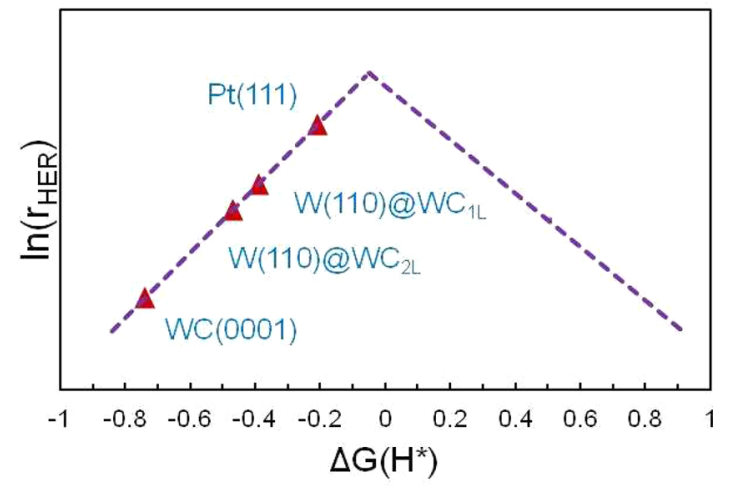

Figure 7. Theoretical volcano curve between the hydrogen evolution reaction rate, $\ln \left(r_{\mathrm{HER}}\right)$, and atomic hydrogen adsorption energy, $\Delta G\left(\mathrm{H}^{*}\right)($ in $\mathrm{eV})$.

top of the volcano curve with the hydrogen adsorption free energy of $-0.21 \mathrm{eV}$ (that is close to $-0.06 \mathrm{eV}$ of the top of the curve), indicating that $\mathrm{Pt}$ is very active for the hydrogen evolution reaction. However, on $\mathrm{WC}(0001)$, the hydrogen adsorption energy is $-0.75 \mathrm{eV}$ which being the highest of the four surfaces studied, resulting in the worst HER reaction rate. The hydrogen adsorption energies on W(110)@WC $\mathrm{WL}_{1 \mathrm{~L}}$ and $\mathrm{W}(110) @ \mathrm{WC}_{2 \mathrm{~L}}$ surfaces are -0.39 and $-0.46 \mathrm{eV}$, respectively, implying that they are significantly more active than $\mathrm{WC}(0001)$ with the two layers of the WC shell on the $\mathrm{W}$ core being slightly less active than the one layer of the WC shell on the W core; the latter is considerably close to $\operatorname{Pt}(111$ ) (with a difference of only $0.18 \mathrm{eV}$ ). The optimized structures of hydrogen adsorption on WC(100)@WC $1 \mathrm{~L}, \mathrm{WC}(100) @ \mathrm{WC}_{2 \mathrm{~L}}$, and WC(0001) surfaces are shown in Figure S12, where $\mathrm{H}$ was adsorbed on the 3-fold hollow sites of $\mathrm{W}$-terminated surfaces.

The W@WC composite has been further evaluated as a catalyst for another important reaction, the electroreduction of aromatic nitro-compounds under ambient conditions. ${ }^{50,51}$

Herein, the as-prepared W@WC did exhibit a significant activity for nitrobenzene (NB) electrocatalytic reduction (Figure 8). As seen in Figure 8b, in which the main data obtained from W@WC, mesoporous WC, nanosized WC, W, and a commercial $\mathrm{Pt} / \mathrm{C}$ catalyst are compared, while the corresponding cyclic voltammograms are shown in Figures 8a and S13, the W@WC displayed a comparable activity to that found for $\mathrm{Pt} / \mathrm{C}$ for NB electroreduction, which is significantly higher than that observed from mesoporous WC, nanosized $\mathrm{WC}$, and $\mathrm{W}$.

The cathodic peak currents of NB reduction (on scanning the potential negatively) for the W@WC, meso-WC, nano-WC, $\mathrm{W}$, and $\mathrm{Pt} / \mathrm{C}$ electrodes are 21.11, 13.78, 6.09, 0, and $25.20 \mathrm{~mA}$ $\mathrm{cm}^{-2}$, respectively (see also Table 1). Furthermore, for the W@ WC, the potential for the cathodic peak is shifted to a less negative voltage in comparison with the meso/nano-WC and $\mathrm{Pt} / \mathrm{C}$, i.e., $-1.17 \mathrm{~V}$ for the W@WC compared with -1.29/$1.28 \mathrm{~V}$ for meso/nano-WC and $-1.25 \mathrm{~V}$ for Pt/C. It is worth highlighting that the W@WC material demonstrates a higher activity for electrocatalytic reduction of NB than a mesoporous WC catalyst, even with only $1 / 12$ th the BET surface area of the meso-WC catalyst.

It is well-documented that the removal of $\mathrm{O}$ from the bulk or the nucleation of the metal phase becomes a rate-limiting factor only when enough $\mathrm{H}_{(\mathrm{ads})}$ is available on the oxide surface. ${ }^{52}$ In this testing system, DMF and TBAP are attracted onto the WC 

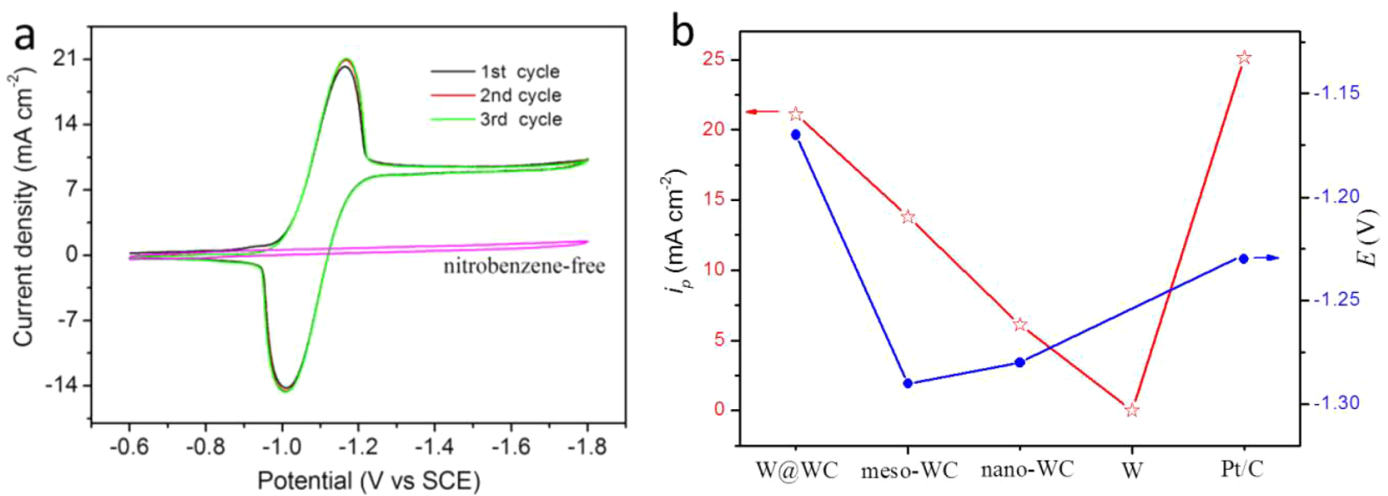

Figure 8. (a) Cyclic voltammograms (CVs) of the prepared W@WC sample in supporting electrolyte of 0.1 M TBAP in DMF solution without (curve: nitrobenzene-free) and with $0.03 \mathrm{M}$ nitrobenzene, respectively; the scan rate is $50 \mathrm{mV} \mathrm{s}{ }^{-1}$. (b) Peak current and peak potential obtained from CV of the prepared W@WC in 0.1 M TBAP in DMF + $0.03 \mathrm{M}$ nitrobenzene; also shown is the peak data obtained from CVs of a mesoporous WC, nanosized WC, $\mathrm{W}$, and a Pt/C in 0.1 M TBAP in DMF + 0.03 M nitrobenzene, for comparison.

Table 1. Comparison of the BET Surface Area and Electrocatalytic Activity Data Obtained from the Cyclic Voltammetry of Nitrobenzene Electrochemical Reduction on the As-Prepared W@WC, Mesoporous WC, W, Nano-WC, and a Commercial $\mathrm{Pt} / \mathrm{C}$ Catalyst

\begin{tabular}{llcl} 
samples & \multicolumn{1}{c}{$S_{\mathrm{BET}}\left(\mathrm{m}^{2} \mathrm{~g}^{-1}\right)^{a}$} & $i_{p}\left(\mathrm{~mA} \mathrm{~cm}^{-2}\right)$ & $E(\mathrm{~V})$ \\
W@WC & 0.51 & $\mathbf{2 1 . 1 1}$ & -1.17 \\
meso-WC & 6.44 & 13.78 & -1.29 \\
$\mathrm{Pt} / \mathrm{C}$ & commercial $(234.10)$ & 25.20 & -1.25 \\
W & 1.46 & 0 & \\
nano-WC & 8.04 & 6.09 & -1.28
\end{tabular}

${ }^{a} \mathrm{BET}$ surface area $\left(S_{\mathrm{BET}}\right)$ was calculated from the linear part of the BET plot.

surface, providing sufficient $\mathrm{H}_{(\mathrm{ads})}$. During the cathodic potential scan, the $\mathrm{O}$ atoms on the surface were reduced at ca. $-0.9 \mathrm{~V}$ (Figure S13c,d) and thus produced vacancies which could in turn coordinate the oxygen atom in the $\mathrm{N}=\mathrm{O}$ group of NB. ${ }^{53}$ The $\mathrm{N}=\mathrm{O}$ bond was polarized and could be attacked and reduced easily by hydrogen atoms adsorbed on the WC at the negative potentials. During the potential cycling experiment, once a surface vacancy is created during the negative scan, the following positive sweep will facilitate the surface $O$ recovering and diffusing to the surface vacancy, and filling it by cycle-forming the surface WC (Figure S13c).

\section{CONCLUSION}

In summary, a simple, yet efficient, one-pot synthesis method has been demonstrated to produce the novel W@WC coreshell architecture with a dodecahedral microstructure, by reducing and carburizing ammonium metatungstate under a $\mathrm{CO} / \mathrm{CO}_{2} / \mathrm{H}_{2} \mathrm{O}$ atmosphere in one-pot reduction-carburization reactions. $\mathrm{H}_{2} \mathrm{O}$ played a key role as a structure-directing agent by mediating the crystal growth of $\mathrm{W}$ along the $\{110\}$ facets to form a stable dodecahedron shape. At the carburization stage, only a thin layer of WC was formed on the surface due to the resistance of the $\{110\}$ facets to carburization. The W@WC exhibited significant electrocatalytic activities toward both hydrogen evolution reaction (HER) and nitrobenzene electroreduction reaction, which being substantially higher than those found for meso- and nano-WC materials, and being comparable to those found for $\mathrm{Pt} / \mathrm{C}$. The experimental results on HER were explained by DFT calculations based on the energy profiles in the hydrogen evolution reactions over WC, W@WC, and Pt model surfaces. The W@WC also showed a high thermal stability and thus may serve as a promising more economical alternative to $\mathrm{Pt}$ catalysts in these important energy conversion and environmental protection applications. The current approach can be extended or adapted to various metals and carbides (see some examples in Figure S14), allowing for the design and fabrication of a wide range of catalytic and other multifunctional materials.

\section{ASSOCIATED CONTENT}

\section{Supporting Information}

The Supporting Information is available free of charge on the ACS Publications website at DOI: 10.1021/acsami.7b04419.

Top and side views of W(100)@WC $1 \mathrm{~W}, \mathrm{~W}(100) @ \mathrm{WC}_{2 \mathrm{~L}}$, and WC(0001) models used in DFT calculations, optimized structures of hydrogen adsorption on $\mathrm{W}(110) @ \mathrm{WC}_{1 \mathrm{~L}} \mathrm{~W}(110) @ \mathrm{WC}_{2 \mathrm{~L}}$ and WC(0001) surfaces, schematic diagram of the experimental setup used, particle size distribution, SEM and STEM micrographs, simultaneous 2D STEM-EDS mapping, TG-DTA, XPS spectra of the W@WC and the contrast, CVs of W@WC, meso-WC, nano-WC, $\mathrm{W}$, and $\mathrm{Pt} / \mathrm{C}$, and SEM images of $\mathrm{MoC}(\mathrm{Mo}), \mathrm{W}_{2} \mathrm{C}$, and $\mathrm{Al}$ samples (PDF)

\section{AUTHOR INFORMATION}

\section{Corresponding Authors}

*E-mail: w.lin@lboro.ac.uk (W.-F.L.).

*E-mail: chuyq@zjut.edu.cn (Y.-Q.C.).

ORCID 을

Wen-Feng Lin: 0000-0002-4256-2058

\section{Notes}

The authors declare no competing financial interest.

\section{ACKNOWLEDGMENTS}

Financial support was provided by Loughborough University and the UK EPSRC (EP/I013229/1), the Natural Science Foundation of Zhejiang Province (LQ15B030004), and the International Science \& Technology Cooperation Program of China (2010DFB63680). We thank Dr. Xia-Zhen Yang for the help in various measurements and useful discussion. 


\section{REFERENCES}

(1) Li, D. X.; Ping, D. H.; Ye, H. Q.; Qin, X. Y.; Wu, X. J. HREM Study of the Microstructure in Nanocrystalline Materials. Mater. Lett. 1993, 18, 29-34.

(2) Hooton, J. C.; Jones, M. D.; Harris, H.; Shur, J.; Price, R. The Influence of Crystal Habit on the Prediction of Dry Powder Inhalation Formulation Performance Using the Cohesive-adhesive Force Balance Approach. Drug Dev. Ind. Pharm. 2008, 34, 974-983.

(3) Ma, C. A.; Brandon, N.; Li, G. H. Preparation and Formation Mechanism of Hollow Microspherical Tungsten Carbide with Mesoporosity. J. Phys. Chem. C 2007, 111, 9504-9508.

(4) Pol, S. V.; Pol, V. G.; Gedanken, A. Synthesis of WC Nanotubes. Adv. Mater. (Weinheim, Ger.) 2006, 18, 2023-2027.

(5) Ganesan, R.; Lee, J. S. Tungsten Carbide Microspheres as a Noble-metal-economic Electrocatalyst for Methanol Oxidation. Angew. Chem., Int. Ed. 2005, 44, 6557-6560.

(6) Nelson, J. A.; Wagner, M. J. High Surface Area $\mathrm{Mo}_{2} \mathrm{C}$ and WC Prepared by Alkalide Reduction. Chem. Mater. 2002, 14, 1639-1642. (7) Chen, Z.; Qin, M. L.; Chen, P. Q.; Jia, B. R.; He, Q.; Qu, X. H. Tungsten Carbide/Carbon Composite Synthesized by Combustioncarbothermal Reduction Method as Electrocatalyst for Hydrogen Evolution reaction. Int. J. Hydrogen Energy 2016, 41, 13005-13013.

(8) Fan, X.; Zhou, H.; Guo, X. WC Nanocrystals Grown on Vertically Aligned Carbon Nanotubes: an Efficient and Stable Electrocatalyst for Hydrogen Evolution Reaction. ACS Nano 2015, 9, 5125-5134.

(9) Zhao, Y.; Kamiya, K.; Hashimoto, K.; Nakanishi, S. Hydrogen Evolution by Tungsten Carbonitride Nanoelectrocatalysts Synthesized by the Formation of a Tungsten Acid/Polymer Hybrid In Situ. Angew. Chem., Int. Ed. 2013, 52, 13638-13641.

(10) Levy, R. B.; Boudart, M. Platinum-Like Behavior of Tungsten Carbide in Surface Catalysis. Science 1973, 181, 547-549.

(11) Bosco, J. P.; Sasaki, K.; Sadakane, M.; Ueda, W.; Chen, J. G. Synthesis and Characterization of Three-Dimensionally Ordered Macroporous (3DOM) Tungsten Carbide: Application to Direct Methanol Fuel Cells. Chem. Mater. 2010, 22, 966-973.

(12) Chen, Z. Y.; Ma, C. A.; Chu, Y. Q.; Jin, J. M.; Lin, X.; Hardacre, C.; Lin, W. F. WC@ meso -Pt Core-shell Nanostructures for Fuel Cells. Chem. Commun. 2013, 49, 11677-11679.

(13) Ma, C. A.; Chen, Z. Y.; Lin, W. F.; Zhao, F. M.; Shi, M. Q. Template-Free Environmentally Friendly Synthesis and Characterization of Unsupported Tungsten Carbide with a Controllable Porous Framework. Microporous Mesoporous Mater. 2012, 149, 76-85.

(14) Ma, C. A.; Liu, W. M.; Shi, M. Q.; Lang, X. L.; Chu, Y. Q.; Chen, Z. Y.; Zhao, D.; Lin, W. F.; Hardacre, C. Low Loading Platinum Nanoparticles on Reduced Graphene Oxide-Supported Tungsten Carbide Crystallites as a Highly Active Electrocatalyst For Methanol Oxidation. Electrochim. Acta 2013, 114, 133-141.

(15) Zellner, M. B.; Chen, J. G. Synthesis, Characterization and Surface Reactivity of Tungsten Carbide (WC) PVD Films. Surf. Sci. 2004, 569, 89-98.

(16) Zellner, M. B.; Chen, J. G. Surface Science and Electrochemical Studies of WC and $\mathrm{W}_{2} \mathrm{C}$ PVD Films as Potential Electrocatalysts. Catal. Today 2005, 99, 299-307.

(17) Esposito, D. V.; Chen, J. G. Monolayer Platinum Supported on Tungsten Carbides as Low-Cost Electrocatalysts: Opportunities and Limitations. Energy Environ. Sci. 2011, 4, 3900-3912.

(18) Ribeiro, F. H.; Dalla-Betta, R. A.; Boudart, M.; Baumgartner, J.; Iglesia, E. Reactions of Neopentane, Methylcyclohexane, and 3,3Dimethylpentane on Tungsten Carbides: The Effect of Surface Oxygen on Reaction Pathways. J. Catal. 1991, 130, 86-105.

(19) Ross, P. N., Jr.; Stonehart, P. The Relation of Surface Structure to the Electrocatalytic Activity of Tungsten Carbide. J. Catal. 1977, 48, $42-59$.

(20) Antolini, E.; Gonzalez, E. R. Tungsten-based Materials for Fuel Cell Applications. Appl. Catal., B 2010, 96, 245-266.

(21) Harnisch, F.; Schroder, U.; Quaas, M.; Scholz, F. Electrocatalytic and Corrosion Behaviour of Tungsten Carbide in Near-neutral $\mathrm{pH}$ Electrolytes. Appl. Catal., B 2009, 87, 63-69.
(22) Eiblmeier, J.; Kellermeier, M.; Deng, M.; Kienle, L.; García Ruiz, J. M.; Kunz, W. Bottom-Up Self-Assembly of Amorphous CoreShell-Shell Nanoparticles and Biomimetic Crystal Forms in Inorganic Silica-Carbonate Systems. Chem. Mater. 2013, 25, 1842-1851.

(23) Herrmann, I. K.; Grass, R. N.; Mazunin, D.; Stark, W. J. Synthesis and Covalent Surface Functionalization of Nonoxidic Iron Core-Shell Nanomagnets. Chem. Mater. 2009, 21, 3275-3281.

(24) Ma, C. A.; Sheng, J. F.; Brandon, N.; Zhang, C.; Li, G. H. Preparation of Tungsten Carbide-Supported Nano Platinum Catalyst and its Electrocatalytic Activity for Hydrogen Evolution. Int. J. Hydrogen Energy 2007, 32, 2824-2829.

(25) Cachet-Vivier, C.; Vivier, V.; Cha, C. S.; Nedelec, J.-Y.; Yu, L. T. Electrochemistry of Powder Material Studied by Means of the Cavity Microelectrode (CME). Electrochim. Acta 2001, 47, 181-189.

(26) Kresse, G.; Hafner, J. Molecular Dynamics for Liquid Metals. Phys. Rev. B: Condens. Matter Mater. Phys. 1993, 48, 13115-13118.

(27) Kresse, G.; Furthmuller, J. Vienna Ab-initio Simulation Package (VASP): The Guide. Phys. Rev. B: Condens. Matter Mater. Phys. 1996, 54, 11169-11186.

(28) Kresse, G.; Hafner, J. Ab Initio Molecular Dynamics for Liquid Metals. Phys. Rev. B: Condens. Matter Mater. Phys. 1993, 47, 558-561.

(29) Kresse, G.; Hafner, J. Ab Initio Molecular-Dynamics Simulation of the Liquid-Metal-Amorphous-Semiconductor Transition in Germanium. Phys. Rev. B: Condens. Matter Mater. Phys. 1994, 49, 1425114269.

(30) Kresse, G.; Furthmuller, J. Efficiency of Ab-Initio Total Energy Calculations for Metals and Semiconductors Using a Plane-Wave Basis Set. Comput. Mater. Sci. 1996, 6, 15-50.

(31) Blochl, P. E. Projected Augmented-wave Method. Phys. Rev. B: Condens. Matter Mater. Phys. 1994, 50, 17953-17979.

(32) Kresse, G.; Joubert, D. From Ultrasoft Pseudopotentials to the Projector Augmented-wave Method. Phys. Rev. B: Condens. Matter Mater. Phys. 1999, 59, 1758-1775.

(33) Perdew, J. P.; Burke, K.; Ernzerhof, M. Generalized Gradient Approximation Made Simple. Phys. Rev. Lett. 1996, 77, 3865-3868.

(34) Norskov, J. K.; Bligaard, T.; Logadottir, A.; Kitchin, J. R.; Chen, J. G.; Pandelov, S.; Stimming, U. Trends in the Exchange Current for Hydrogen Evolution. J. Electrochem. Soc. 2005, 152, J23-J26.

(35) Rossmeisl, J.; Logadottir, A.; Norskov, J. K. Electrolysis of Water on (Oxidized) Metal Surfaces. Chem. Phys. 2005, 319, 178-184.

(36) Esposito, D. V.; Hunt, S. T.; Kimmel, Y. C.; Chen, J. G. ChemInform Abstract: A New Class of Electrocatalysts for Hydrogen Production from Water Electrolysis: Metal Monolayers Supported on Low-Cost Transition Metal Carbides. J. Am. Chem. Soc. 2012, 134, 3025-3033.

(37) Greeley, J.; Jaramillo, T. F.; Bonde, J.; Chorkendorff, I.; Norskov, J. K. Computational High-throughput Screening Of Electrocatalytic Materials for Hydrogen Evolution. Nat. Mater. 2006, 5, 909-913.

(38) Sims, R. E. H. The Brilliance of Bioenergy in Business and in Practice; James \& James (Science Publishers) Ltd.: London, 2002.

(39) Asada, N.; Yamamoto, Y.; Shimatani, K.; Honkawa, S.; Miyake, M. Particle Size of Fine Grain WC by the 'Continuous Direct Carburizing Process'. Met. Powder Rep. 1990, 45, 60-64.

(40) Venables, J. A. Introduction to Surface and Thin Film Processes; Cambridge University Press: Cambridge, 2000.

(41) Zhang, J. M.; Wang, D. D.; Xu, K. W. Calculation of the Surface Energy of Bcc Transition Metals by Using the Second NearestNeighbor Modified Embedded Atom Method. Appl. Surf. Sci. 2006, 252, 8217-8222.

(42) Wang, S. L.; He, Y. H.; Fang, X. S.; Zou, J.; Wang, Y.; Huang, H.; Costa, P. M. F. F.; Song, M.; Huang, B. Y.; Liu, C. T.; Liaw, P. K. Bando, Y.; Golberg, D. Structure and Field-Emission Properties of Sub-Micrometer-Sized Tungsten-Whisker Arrays Fabricated by Vapor Deposition. Adv. Mater. (Weinheim, Ger.) 2009, 21, 2387-2392.

(43) Inumaru, K. Sponge Crystal": a Novel Class of Microporous Single Crystals Formed by Self-assembly of Polyoxometalate $\left(\mathrm{NH}_{4}\right)_{3} \mathrm{PW}_{12} \mathrm{O}_{40}$ Nanocrystallites. Catal. Surv. Asia 2006, 10, 151160 . 
(44) Smart, L. E.; Moore, E. A. Solid State Chemistry: An Introduction, 3rd ed.; CRC Press: Boca Raton, FL, 2005.

(45) Abdullaeva, Z.; Omurzak, E.; Iwamoto, C.; Okudera, H.; Koinuma, M.; Takebe, S.; Sulaimankulova, S.; Mashimo, T. High Temperature Stable WC $\mathrm{C}_{1-\mathrm{x}} @ \mathrm{C}$ and TiC@C Core-shell Nanoparticles by Pulsed Plasma in Liquid. RSC Adv. 2013, 3, 513-519.

(46) Wagner, C. D., Riggs, W. M., Davis, L. E., Moulder, J. F., Muilenberg, G. E., Eds. Handbook of X-ray Photoelectron Spectroscopy; Perkin-Elmer Corporation: Eden Prairie, MN, 1979.

(47) Liu, N.; Rykov, S. A.; Chen, J. G. A Comparative Surface Science Study of Carbide and Oxycarbide: the Effect of Oxygen Modification on the Surface Reactivity of C/W(111). Surf. Sci. 2001, 487, 107-117.

(48) Kado, T. Structural and Mechanical Properties of Tungsten Oxycarbide Films Synthesized by Inductively Coupled RF PlasmaAssisted Magnetron Sputtering. Vacuum 2004, 76, 165-168.

(49) Lin, W. F.; Jin, J. M.; Christensen, P. A.; Scott, K. Structure and Reactivity of the $\mathrm{Ru}$ (0001) Electrode Towards Fuel Cell Electrocatalysis. Electrochim. Acta 2003, 48, 3815-3822.

(50) Schrinner, M.; Ballauff, M.; Talmon, Y.; Kauffmann, Y.; Thun, J.; Möller, M.; Breu, J. Single Nanocrystals of Platinum Prepared by Partial Dissolution of Au-Pt Nanoalloys. Science 2009, 323, 617-620.

(51) Xiao, F. An Efficient Layer-By-Layer Self-Assembly of Metal$\mathrm{TiO}_{2}$ Nanoring/Nanotube Heterostructures, M/T-NRNT $(\mathrm{M}=\mathrm{Au}$, $\mathrm{Ag}, \mathrm{Pt}$ ), for Versatile Catalytic Applications. Chem. Commun. 2012, 48, $6538-6540$

(52) Rodriguez, J. A.; Hanson, J. C.; Frenkel, A. I.; Kim, J. Y.; Pérez, $M$. Experimental and Theoretical Studies on the Reaction of $\left.\mathrm{H}_{2}\right)$ with Nio: Role of $\mathrm{O}$ Vacancies and Mechanism for Oxide Reduction. J. Am. Chem. Soc. 2002, 124, 346-354.

(53) Xiong, J.; Chen, J. X.; Zhang, J. Y. Liquid-phase Hydrogenation of O-Chloronitrobenzene over Supported Nickel Catalysts. Catal. Commun. 2007, 8, 345-350. 